years time. By that time Concord will be operating, and is unlikely to be trapped by noise legislation. If the noise level established means that the Boeing aircraft has to fly more slowly than its design speed, economy of operation will suffer severely, and indeed may make the SST quite uneconomic over land. A study commissioned by the FAA and carried out by the North American Aviation Co., however, indicates that the penalty of flying SSTs at subsonic speeds over land would be "not intolerable". People's interpretation of this depends on whether they build aeroplanes or operate them.

Aircraft builders are, of course, notoriously optimistic. This optimism is not always shared by the airlines, or by the political paymasters of the aircraft industry. The sacking of General Puget, until last week head of Sud Aviation, the nationally owned French airframe company which is collaborating with the British Aircraft Corporation in the Concord project, will diminish by one the number of enthusiasts in service. General Puget's successor, M. Maurice Papon, is known as a gifted administrator.

\section{Swinging Wings}

BRITISH aerodynamic engineers are at once envious and optimistic about the outcome of the development work to be carried out by the Boeing Aircraft Company before its supersonic aircraft can take the air. The problem of matching the two wings together in such a way as not to upset the lateral stability of the aircraft has been dealt with on the FIIl fighter aircraft by linking the two halves of the wing together mechanically with a common jack. Because the Boeing design has separate hinges for each half wing, and because these lie athwart the passenger cabin, it will be necessary to link the two halves together with an clectro-mechanical servo-system. Apparently even as much as a degree or so of mis-alignment between the two wings would not be beyond the capacity of the roll control system, partly because the outer surfaces of wings contribute only a small proportion of the total lift.

The problem of designing hinges which can move reliably and yet transmit lifting forces comparable with the weight of the aircraft appears also not to be a cause for worry. Prototypes of hinges with dry bearings and lubricated bearings have been carried out. There appear to be no problems in using materials such as PTFE as dry lubricants or in using ordinary petroleum lubricants. Problems arising from the high temperatures at which some supersonic designs will operate may be more serious, particularly because they make it necessary to introduce new materials for incidental purposes such as the operation of hydraulics and lubrication systems.

Aerodynamic engineers therefore remain preoccupied with problems closer to the mainstream of classical aerodynamics. Thus it is necessary to design supersonic aircraft such as the Bocing SST so that they can if necessary land with the wings fully swept back if, for some reason, the wing moving mechanism should fail. In this kind of mishap, supersonic aircraft would necessarily have to seek out airfields with long runways and use up spare fuel before attempting to land at what would inevitably be a hair-raising landing specd. Another problem which excites lively interest is that of striking a continuing balance between the centre of aerodynamic lift and the centre of gravity of a supersonic aireraft with swept wings. On the face of things, it would appear that moving back the wings would leave the front of an aircraft unsupported. British aerodynamicists claim that a decade ago Dr. Barnes Wallis showed that a clever distribution of the weight of an aircraft could go a long way to reduce the severity of this problem.

\section{Venus Observed}

THE first observations of water vapour in the atmosphere of Venus from ground based observatories are described in two notes published in the current issue of the Astrophysical Journal. Hitherto, the identification of water in the atmosphere of Venus has been based on observations from balloon flights over the United States in the early sixties. Both the groups now reporting have worked with water vapour absorption lines in the near infra-red $(8189 \AA$ and $8193 \AA$ ) and have been able to recognize Doppler shifts due to the motion of Venus at different parts of its orbit about the Sun. The detection of water vapour in planetary atmospheres is necessarily complicated by the presence of water in the atmosphere of the Earth, but Doppler shifts make it possible to separate absorption due to the two sources.

M. J. S. Belton and D. M. Hunten worked with spectra of Venus formed by the $40 \mathrm{ft}$. spectrograph of the solar telescope at the Kitt Peak National Observatory (Astrophysical Journal, 146, 307; 1966). The second note in the same issue of the journal (ibid., $146,328 ; 1966)$ is by Hyron Spinrad and Stephen J.' Shawl of the University of California at Berkeley, who have examined coudé spectrograms of Venus taken at the Lick Observatory. The Doppler shift of the spectra due to the movement of Venus in its orbit amounted to between 0.2 and $0.3 \AA$, and the successful identification of water vapour from the Earth has thus been made possible only by the extremely high dispersion of the spectrographic instruments used. Both groups of astronomers have been able to estimate the amount of water in the atmosphere of Venus above the clouds. The first group has set an extreme upper limit of 125 microns to the amount of precipitable water, and the second has estimated the amount of water at 60 microns, emphasizing that this estimate is necessarily somewhat crude.

\section{Luna 13}

LUNa 13, the Russian spacecraft which made a soft landing on the Moon on December 24, 1966, has now completed its mission. Pictures taken by Luna 13 from the landing site in the Ocean of Storms, 250 miles from the site where Luna 9 landed, show that there are no formations larger than $3.5 \mathrm{~km}$ in diameter within $62 \mathrm{~km}$ of the landing site, and no big formations rising above the ground. The spacecraft, inclined at $16^{\circ}$ to the local vertical, completed a panoramic sweep and was able to distinguish objects 1.5 to $2 \mathrm{~mm}$ in size at a distance of $2 \mathrm{~m}$. The spacecraft containcd electronic programme devices, chemical batteries, and a temperature regulating systcm, and had four petal and four rod antennae, a television camcra, and two devices for measuring soil depth and density. 